\title{
Contar a los desaparecidos en Colombia. Educación, lectura y memoria
}

\section{// An account of missing in \\ Colombia Education, reading \\ and memoir \\ //Contar sobre os desaparecidos na Colômbia. Educação, leitura e memoria}

Revista Colombiana

de Educación, N. 62.

Primer semestre de 2012,

Bogotá, Colombia.

Nylza Offir García Vera*

\begin{abstract}
Adelanta la Maestría en Educación en la Universidad Pedagógica Nacional, especialista en la Enseñanza del Español y la Literatura y Licenciada en Pedagogía de la Universidad de Pamplona. Docente-investigadora de la Facultad de Educación de la Universidad Pedagógica Nacional, vinculada al grupo de investigación Educación superior, conocimiento y globalización, en la línea Discursos y prácticas de la educación superior. Correo electrónico: nylzao@yahoo.es.
\end{abstract}

\section{Resumen}

El artículo dimensiona el drama de una realidad en la historia reciente de Colombia: la desaparición forzada. Se propone, a través de una reflexión amplia que adopta diversos momentos y escenarios, así como también distintas fuentes informativas y narrativas, contar esta historia a los jóvenes que se educan en nuestras universidades. Para ello, la experiencia de la lectura literaria como un acontecimiento que permite algo más que informarnos sobre el tema, emerge como condición de posibilidad para vivir, sentir, pensar y memorar con los otros lo que significa esta suerte de purgatorio, esta espera sin fin.

\section{Abstract}

This paper offers a view about a real drama in Colombia's recent history: forced disappearance. So the proposal is telling this to young people who are educated in our universities by a reflection, taking several moments and scenarios as well as other information and narrative sources. Then a literary reading experience emerges as an event that allows more than just say something about it, and a chance for living, feeling, thinking and remembering with others this kind of endless purgatory.

\section{Resumo}

O artigo dimensiona o drama de uma realidade histórica recente da Colômbia: o desaparecimento forçado. Propõe-se, em seguida, através de ampla reflexão - que adota diversos momentos e cenário, assim como distintas fontes informativas e narrativas -, a contar essa história aos jovens educados em nossas universidades. Para isso, a experiência da leitura literária, como um acontecimento que permite algo mais que informar sobre o tema, emerge como uma condição de possibilidade para viver, sentir, pensar e lembrar com os outros o que significa este tipo de purgatório, esta espera sem fim.

\section{Palabras Clave}

Desaparición forzada, memoria, educación, experiencia de la lectura, literatura.

\section{Keywords}

Forced disappearance, memoir, education, reading experience, literature.

\section{Palavras chave}

Desaparição forçada, memória, educação, experiência de leitura, literatura. 
Con la ilusión que se anida en los corazones de quienes deseamos que tus manos sigan acariciando el viento.

Que tus ojos sigan presenciando al majestuoso sol en un atardecer.

Que tus piernas dancen juguetonas bajo la lluvia. Que tu corazón siga latiendo en algún lugar de la Pachama-

ma.

La esperanza no se pierde. Ella se nutre de la fuerza vital de tu sonrisa y de tu lucha. A Sandra Viviana Cuellar Gallego Joven ambientalista desaparecida el 17 de febrero de 2011 en Cali, Colombia.

\section{A manera de prolegómenos}

En Colombia, como en un acto macabro de magia, se desaparecen las personas. Las cifras oficiales de desaparecidos son de dimensiones escalofriantes. Los medios introducen como una nota más los casos sobre 'desaparición forzada', al tiempo que algunos columnistas y defensores de derechos humanos intentan preservar la memoria de esta tragedia a través de sus crónicas y denuncias. En medio de las cifras podemos hallar uno que otro relato o informe que nos acerca al drama vivido por los familiares de los miles de desaparecidos en el país.

En noviembre de 2010 apareció en el medio literario una novela que dibuja el rostro de uno de estos tantos desaparecidos: Ramiro Díaz, un mesero de la cafetería que salió con vida del Palacio de Justicia en aquel noviembre de 1985, pero del que luego no se volvió a tener noticia alguna' . El autor de este libro crea una ficción que nos aproxima literariamente a una víctima de este delito. Pero, ¿qué puede enseñarnos el dolor de las familias a quienes las han condenado a Vivir sin los otros? ¿Por qué hemos de preservar en nuestra memoria colectiva esta tragedia y luchar contra su olvido? ¿Qué lugar tienen la educación, la lectura y la literatura en este escenario?

Estas son algunas de las preguntas que atraviesan el presente texto, cuyo propósito es indagar por las posibilidades que tiene la lectura, especialmente la lectura literaria en tanto experiencia que nos enseña aquello que también le compete a la educación: el saber sobre nosotros mismos en el marco de una guerra que degrada la condición humana. Aun cuando referiremos algunas 
fuentes documentales que permiten situar en cifras y en informes el fenómeno de la desaparición forzada y su significado para la sociedad, se propone el trabajo pedagógico con cierto tipo de textos narrativos en los cuales emerge la posibilidad de resguardar en la memoria literaria aquello que precisa ser contado: la historia de los desaparecidos en Colombia.

Contar esta historia, leerla y hacerla propia, es imprescindible para preservar la memoria histórica de un país que todavía no se recupera de esta tragedia y que vive aún en medio de un conflicto armado. Todo proyecto educativo que se piense para las nuevas generaciones, requiere contar además con esta historia, en el entendido de que educar es, también y primordialmente, un asunto de orden ético.

\section{Educación y lectura: del acto pedagógico al acto ético y político}

Cuando se alude al tema de la lectura, esta aparece vinculada, cada vez con más frecuencia, a las nociones de comprensión, de hábito y de competencia. Instaurado como está en el discurso pedagógico oficial, el saber leer se concibe como una habilidad para salir avante de la educación básica. En el caso de la educación superior es condición sine qua non para apropiar los contenidos y saberes propios de una disciplina y de una profesión.
En una reciente investigación sobre el leer y el escribir en la universidad colombiana, tales prácticas en la academia resultan ser altamente heterónomas y se vinculan de modo fuerte con las actividades evaluativas de los docentes y con la formación propiamente disciplinar ${ }^{2}$. Los cursos de lengua se erigen allí en los primeros ciclos de fundamentación de las carreras universitarias, como una posibilidad para integrar estrategias que permitan abordar los textos académicos y científicos del campo profesional en el que se forma, pero también como un modo de 'suplir' una supuesta ineficiencia del sistema escolar anterior que no logra formar lectores competentes. Para algunos estudiantes, sobre todo de áreas como la agricultura, los servicios, el derecho y las ciencias básicas, estos cursos son el único espacio curricular en el cual acceden a géneros de carácter informativo y narrativo: allí se tiene muchas veces la oportunidad de leer textos periodísticos y textos literarios, esto es, aproximarse a otras lecturas y realidades.

En este escenario, la preocupación fundamental, además legítima y necesaria, es que los futuros

2 Cfr. Sistema Integral de Gestión de Proyectos, Colciencias. Proyecto: ¿Para qué se lee y se escribe en la universidad colombiana? Un aporte a la consolidación de la cultura académica del país [CódigoPREOO439015708]. Proyecto desarrollado entre el 2009 y el 2011 que vinculó a 17 universidades públicas y privadas del país. Esta referencia a algunos resultados nacionales -que próximamente saldrán a la luz pública- la hago como co-investigadora del proyecto en el que participé a nombre de la Facultad de Educación de la Universidad Pedagógica Nacional. 
profesionales accedan a los códigos propios de su campo y se conviertan así en lectores autónomos. Pero por importante que sea esta tarea, la dimensión académica de la lectura para educar a las nuevas generaciones no es suficiente. Más allá de estas razones pragmáticas o científicas, es también crucial en la educación superior abordar la dimensión poética y política del acto de leer, en su relación con la ética y la ciudadanía; inscribir en el horizonte de la formación la lectura como posibilidad de conocimiento, de comprensión o de experiencia de un país ignorado y extraño para una gran mayoría de nuestros jóvenes: el país que vive en conflicto y en guerra ${ }^{3}$.

Si educar es un acontecimiento ético, como nos lo recuerdan Bárcena y Mélich (2000), la educación no debería preocuparse por enseñar solo lo más elaborado y excelso de la cultura: las artes, las ciencias, las disciplinas, los desarrollos científicos, técnicos y tecnológicos, entre otros, sino también tendría que ocuparse de mostrar lo más inhumano y la barbarie que se halla en nuestra propia historia de civilización. Tanto la cultura como la educación, nos dicen los autores, "tienen que ser repensadas, pues su herencia ya no es el humanismo, sino una memoria herida de la civilidad y la cultura, o dicho de otro modo, la cultura de lo inhumano" (p. 36).

Quienes trabajamos en el tema de la lectura como objeto de conocimiento y como objeto pedagógico, sabemos bien que el sentido de enseñar a leer se corresponde no solo con el propósito de que nuestros estudiantes comprendan el mundo físico, social y cultural que les rodea; sino que también, y fundamentalmente, tiene que ver con la formación de ciudadanos. Pero no puede haber ciudadanía allí donde no se informa sobre las condiciones históricas, políticas y económicas en las que se ha estado inmerso y en las que se vive el día a día. No hay ciudadanía sin lectores críticos, sin memoria de país y sin historia. Allí donde la historia oficial ha borrado el relato de los vencidos. Allí donde "la amnesia, la desmemoria, el olvido, se edifican con el silencio" (Mendoza, 2004, p. 10). Es por eso que para impedir la reedición de la barbarie, nos dicen de nuevo Bárcena y Mélich, necesitamos más civilización y al mismo tiempo otra clase de civilización (2000, p. 46).

Quizás es Paulo Freire en su apuesta por una educación como práctica de libertad, que puso además el acento inicial de su

3 El tema es un asunto que pareciera ser exclusivo de aquellos estudiantes y de sus profesores que se forman en las ciencias sociales y en algunas humanidades. 
trabajo pedagógico en la alfabetización de los oprimidos, quien más nos ilustra del cómo se puede pasar de un acto pedagógico a un acto político a través de la lectura: enseñar a leer el mundo que habitamos en su pasado y en su presente $y$ no solo reproducirlo, intentar reescribirlo como parte de una lectura crítica de esa realidad y de un nuevo comienzo, de otro futuro, es en sentido pleno educar para Freire. Leer nos exige así una transformación intelectual de los sujetos, pero también una decisión de transformar el mundo ${ }^{4}$. De tal manera que leer y escribir no son solo técnicas de dominio cognitivo o psicomotriz, sino que comportan siempre actitudes de creación y recreación: "La lectura implica una experiencia de autoformación y por ello deriva siempre en una postura activa del sujeto frente al contexto" (Cfr. Freire, 1997, p. 108).

En esta perspectiva, la lectura recobra otros sentidos posibles en el acto educativo, sea en el nivel más elemental en el sentido de fundamental que se da en la escuela básica o en la educación superior que se ofrece en las universidades. Pero no se trata de una lectura que nace del lenguaje de la previsibilidad y del control o del dominio psicológico de una habilidad, pues este tipo de con-

4 Quienes hemos seguido de cerca la pedagogía freiriana podríamos afirmar que una posible síntesis de sus enseñanzas sugiere la posibilidad de entender que la historia es una construcción de los hombres y que por eso son ellos los llamados a transformar su presente y su futuro y construir otra historia. cepciones son agenciadas con rigor por las instancias oficiales MEN, con todas sus baterías de evaluación de competencias lectoras: desde las pruebas SABER hasta los ECAES.

De lo que se trata aquí es de comprender que formar lectores significa algo más que proveer estrategias y hábitos para responder a las tareas escolares y de ahí a las exigencias de la academia universitaria, para dar paso a una concepción en la cual la lectura sea también afectación del sujeto, de tal forma que no solo su cognición o sus pensamientos sean transformados, sino también su propia sensibilidad, su modo de vivir y habitar el mundo. Es quizá lo que nos intenta decir George Steiner cuando afirma que "quien haya leído La Metamorfosis de Kafka y pueda mirarse impávido al espejo, será capaz, técnicamente, de leer la letra impresa, pero es un analfabeto en el único sentido que cuenta" (p. 27)

\section{La lectura como experiencia: "Eso que me pasa"}

Para abrir paso a esta afectación del sujeto en el acto de leer es propicio repensar la lectura como experiencia o como acontecer humano, tal y como nos lo propone Jorge Larrosa

5 En una reciente conferencia de Jorge Larrosa, en el IX Taller Nacional para la Transformación de la Formación Docente en Lenguaje, realizado en Medellín entre el 10 y el 12 de octubre de 20011, propuso al público pensar esta cita de Steiner y cambiar a Kafka por cualquier autor clásico del pensamiento o de la literatura. 
(2008, p. 89). Para este autor, la experiencia supone un acontecimiento exterior o fuera del sujeto, pero a su vez es en el sujeto en el que tiene lugar tal experiencia. Experiencia es "eso que me pasa", afirma literalmente, de ahí que toda experiencia implique un movimiento de ida y vuelta:

Un movimiento de ida porque la experiencia supone un movimiento de exteriorización, de salida de sí mismo, de salida hacia afuera, un movimiento que va al encuentro con eso que pasa, al encuentro con el acontecimiento. $Y$ un movimiento de vuelta porque la experiencia supone que el acontecimiento me afecta a mí, que tiene efectos en mí, en lo que soy, en lo que yo pienso, en lo que yo siento, en lo que yo sé, en lo que yo quiero (Larrosa, 2008, p. 90).

Siguiendo al autor, toda experiencia involucra un tránsito, un padecimiento y una transformación en el sujeto. Por ello la experiencia nos forma y transforma a la vez. $Y$ es precisamente esta concepción la que permite situar el vínculo entre educación y lectura. La lectura de un libro es una experiencia formativa solo si en nuestra relación con el texto algo nos pasa, algo le pasa al lector. Es, nos recuerda Larrosa con Steiner, mirarse en el espejo de otra manera: "Pensar la lectura como formación implica pensarla como una actividad que tiene que ver con la subjetividad del lector, no solo con lo que el lector sabe, sino con lo que es [...] como algo que nos constituye o nos pone en cuestión en aquello que somos" (p. 96).

$\mathrm{Si}$ bien es en la experiencia de lectura de un texto literario dada su dimensión estética en donde se hallan mayores posibilidades para que en el sujeto suceda esa suerte de sensibilización, de transformación y de formación, Larrosa alude a cualquier tipo de texto o de autor. En ese sentido, señala que lo importante no es lo que el texto o el autor diga, piense o sienta, sino aquello que el sujeto pueda decir, pensar o sentir a partir lo leído. En esa misma perspectiva, Jurado (2001) nos señala: "La lectura de un texto literario, científico, filosófico, o de cualquier otro género es, sin duda, una experiencia de iniciación o una prueba de paso: después del viaje por la selva de los símbolos, en todo lector se opera una transformación" (p. 95).

No obstante, de nuevo Larrosa nos recordará como hoy es cada vez es más escasa la posibilidad de que la lectura sea una 
experiencia para el sujeto. El mundo moderno que se nos presenta bajo las etiquetas de una 'sociedad de la información', ligada a la vez a la inmediatez de las cosas y a la condición efímera de las opiniones, no da lugar a esta posibilidad:

El sujeto de la información sabe muchas cosas, se pasa el tiempo buscando información, cada vez sabe más, cada vez está mejor informado, pero en esa obsesión por la información y por el saber (pero por el saber no en el sentido de "sabiduría" sino en el sentido de "estar informado"), lo que consigue es que nada le pase (Larrosa, 2008, p. 105).

Además de que nada nos pasa, cada acontecimiento que viene unido con la noticia o información a la que accedemos impide también la memoria, la huella. La vertiginosa carrera de los hechos y el modo como se presenta ante nuestros ojos no permite al lector exponerse el tiempo suficiente. Ante la información al sujeto nada le acontece, nada le sucede, nada le pasa, nada le llega, nada le afecta, nada le amenaza, nada le hiere (Cfr. 2008, pp. 104-108).

Es quizá esta sensación del noacontecimiento, del no-suceso, de la no-experiencia, de la no-lectura, la que puede estar teniendo lugar en nuestro país, por ejemplo, cuando en recientes noticias leemos que en los últimos años el número de desapariciones en Colombia alcanzó dimensiones escalofriantes:

"La desaparición forzada en Colombia alcanzó dimensiones escalofriantes", denunció el lunes el representante de la oficina del Alto Comisionado de Naciones Unidas para los derechos humanos, Christian Salazar, quien atribuyó a la fuerza pública gran parte de la responsabilidad. "Las cifras que conocemos indican dimensiones escalofriantes", dijo Salazar al revelar que 15.600 personas han sido desaparecidas presuntamente de manera forzada en Colombia, de un total de más de 57.200 desaparecidos que figuran en el Registro Nacional de Desaparecidos. Esas desapariciones forzadas -entre las que se cuentan más de 3.000 mujeres e igual número de menores de 20 años- fueron "cometidas por agentes del Estado y fuerzas paramilitares que colaboran con ellos", dijo Salazar (Agencia EFE, 2011)(ONU, 2011).

La pregunta es: ¿qué dicen, qué piensan, qué sienten los ciudadanos 
de un país como Colombia frente a la lectura de una noticia como esta? La información señala que son "quince mil seiscientas personas víctimas de desaparición forzada en Colombia de un total de 57.200 desaparecidos en las últimas décadas", contando solo con aquellos que figuran efectivamente en el Registro Nacional. Sin duda, como nos lo propone Larrosa al situar la lectura como experiencia, este tipo de información que leemos no nos afecta en lo propio, es decir, no nos acontece. Es, efectivamente, un "cúmulo de noticias fragmentarias y aceleradamente caducas... Vemos el mundo pasar ante nuestros ojos y nosotros permanecemos exteriores, ajenos, impasibles" (Larrosa, 2008, p. 96).

\section{Fuentes documentales sobre desaparecidos en Colombia: ¿Qué se lee en estos textos? ¿Qué acontece en nosotros?}

El tema de la desaparición forzada en Colombia es prácticamente un asunto ajeno y exterior al común de los ciudadanos. De este se ocupan especialmente personas que pertenecen a instancias oficiales comprometidas con el mismo, algunos comunicadores o periodistas críticos, ciertos grupos de investigación que estudian en diferentes perspectivas esta práctica criminal en el país y varias organizaciones de derechos humanos que trabajan con las propias víctimas en la búsqueda de sus familiares, y en la exigencia de memoria, verdad, justicia y reparación ante el Estado colombiano ${ }^{6}$.

En los últimos años este ha sido un tema noticioso en los medios, pero marginal frente a su dimensión humana, política y social. Desde el 2006, por ejemplo, de acuerdo con Semana, se sabe que la misma Fiscalía de la Nación reconoció 7.702 casos de desaparición forzada (entre 1982 y 2005), la Procuraduría, 829 casos (entre 1993 y 2005), la Vicepresidencia de la República, 4.177 (entre 1997 y 2005) y Medicina Legal 1.014 víctimas (entre 2005 y 2006) ${ }^{7}$. En el 2009, en la nota "El crimen invisible", el mismo

6 Quizá la organización más representativa en Colombia nace precisamente del Movimiento Nacional de Víctimas de Crímenes de Estado, MOVICE, que dedica gran parte de su trabajo a luchar contra la impunidad frente a este crimen. Asimismo, desde 1982 se creó la Asociación de Familiares de Detenidos y Desaparecidos -ASFADDES- que hoy en día se constituye un referente obligado de resistencia y de lucha contra el olvido.

7 Cfr. www.semana.com [en línea] "Los desaparecidos forzados en Colombia ¿cuántos se buscan? Miércoles 15 de noviembre de 2006. 
semanario publicó otro nuevo informe en el que señala: "La Fiscalía tiene confirmados hasta ahora 25.000 casos de desaparición forzada en el país. Hace dos años, cuando se pensaba que eran 10.000, nadie imaginaba la magnitud del tema" ${ }^{\prime \prime}$. Según esta información, nuestra tragedia es aún peor que la sufrida por los países del Cono Sur en épocas de dictadura en las que se revivió la tenebrosa noche y niebla nazista, como lo registra también un artículo de El Tiempo:

51.000 y contando. Es la cifra de personas "desaparecidas" en Colombia a lo largo de las últimas décadas y que hace parte de un nuevo informe publicado en Washington que usa como fuente para sus conclusiones a la Fiscalía General y la Comisión Nacional de Búsqueda, creada por el Congreso en 2007 para llegar al fondo del asunto [...] Según el reporte, de acuerdo con la Fiscalía, de esas personas al menos 32.000 serían "desapariciones forzosas", cometidas por guerrillas, paramilitares y miembros de la Fuerza Pública. De
8 Cfr. www.semana.com [en línea] "El crimen invisible". Sábado 17 de octubre de 2009. Allí se señala que aunque las cifras no están exentas de controversia, "La mayoría de las desapariciones ocurrió entre 1996 y 2003 y se le atribuye a grupos paramilitares". acuerdo con los autores, si bien se piensa en Chile o Argentina cuando se habla de este tipo de desapariciones, las nuevas estadísticas le están dando dimensión a esta tragedia y ponen a Colombia a la cabeza de este tipo de crímenes en el mundo" [...] Para los autores del estudio, lo peor es que la cifra podría ser mucho más alta9.

En efecto, eso es lo que dice el informe referido en esta nota periodística. Bajo el título "Rompiendo el silencio. En la búsqueda de los desaparecidos en Colombia", el Grupo de trabajo sobre asuntos latinoamericanos y la Oficina en los Estados Unidos sobre Colombia, señala, entre otros $(2010$, p.3):

Es poca la atención que se presta a las desapariciones en Colombia. La razón de ello podría ser simplemente porque el número de víctimas de asesinatos, masacres, homicidios y bajas en combate en los que existen cuerpos es tan alto que las desapariciones quedan fuera del foco de interés. La habilidad del gobierno en proyectar una imagen de éxito también

9 Cfr. www.eltiempo.com [en línea] "Son 51 mi los desaparecidos en Colombia en las últimas décadas". 13 de diciembre de 2010 
ha contribuido para que las desapariciones, junto con otros abusos de derechos humanos, sean menos visibles.

Pero, ¿quiénes son las víctimas? En el mismo informe se afirma que "las víctimas de desapariciones forzadas en Colombia incluyen a defensores de derechos humanos, sindicalistas, afrocolombianos, indígenas, jóvenes y niñas adolescentes de zonas rurales en conflicto. Integrantes de la comunidad LGBT, habitantes de la calle y otros identificados como 'indeseables' (2010, p. 5)".

Entre los victimarios y responsables del delito, de acuerdo con la Comisión, están "tanto las fuerzas armadas y policiales así como todos los grupos armados ilegales". Sobre estos últimos se señala:

Las guerrillas asesinaban y desaparecían personas, y en muchas ocasiones los secuestros y el reclutamiento forzado, incluyendo el reclutamiento de menores, fue catalogado como desapariciones. Cuando en la década del 90 creció el fenómeno paramilitar, también aumentaron los casos de personas que se tenían por desaparecidas a manos de las fuerzas paramilitares -grupos armados de derecha que a menudo recibían la colaboración de integrantes de las fuerzas armadas de Colombia- (2010, p. 5).

Asimismo, se sostiene que "los colombianos recién están empezando a ver la dramática dimensión del número de desaparecidos por paramilitares" (2010, p. 5):

Los paramilitares solían destruir los cuerpos de sus víctimas, quemándolos o cortándolos con motosierras, y los enterraban en fosas comunes dentro de fincas, a las orillas de los ríos o a las afueras de los cementerios, o los arrojaban a los ríos. Surgieron reportes sobre la existencia de hornos crematorios que eran usados por los paramilitares para desaparecer los cuerpos de sus víctimas en el Catatumbo e incluso en las afueras de Medellín (p. 5).

Lo más dramático es que en tales desapariciones, que se nos presentan similares a un acto de magia macabro, como ya se anotó al comienzo, no solo desaparecen las víctimas, también desaparecen los que buscan a los desaparecidos: "Tanto denunciar las desapariciones, como investigarlas, así como realizar las exhumaciones, son tareas peligrosas, especialmente en un contexto donde persiste el conflicto armado. Según la Comisión 
Nacional de Búsqueda, un equipo de exhumación desapareció, y otro fue atacado y uno de sus miembros fue asesinado" (p. 14) ${ }^{10}$.

Pero, ¿cómo se instaura este tipo de crimen en el 'corazón' de una sociedad? ¿Qué móviles tejen esta absurda realidad? ¿Qué lo hace posible? ¿Por qué sucede? ¿Qué implicaciones tiene para los familiares? y ¿cómo afecta la existencia y la historia de un colectivo social? Además del informe mencionado existen en Colombia otros trabajos de investigación sobre este tema que intentan dar respuesta a muchos de estos interrogantes. La Fundación Dos mundos, por ejemplo, en su edición especial sobre desaparición forzada (2006), elabora un panorama psicosocial de esta práctica criminal en el país. Allí se advierte que lejos de ser una práctica superada, fue y sigue siendo una realidad sobre la cual no se conocen sus verdaderas dimensiones. Además, se corresponde con una acción sistemáticamente planeada: "La desaparición forzada se caracteriza generalmente por su sistematicidad. Rara vez es una práctica ais-

10 Lo más preocupante de todas estas cifras es que, en términos de justicia para las desapariciones forzadas, según este informe, la Ley 957 de Justicia y Paz representa un retroceso en tanto: "Reduce el término de la sentencia por el crimen de desapariciones de 25 a 60 años dispuesto en la ley, a un máximo de ocho años para los que confiesan sus crímenes. De igual manera es muy preocupante el reducido número de personas que han sido sentenciadas dentro del marco de Justicia y Paz. Cinco años después de la promulgación de la ley, solo dos paramilitares han sido condenados [...]" (2010, p. 14) lada, posee una lógica y objetivos subyacentes, como la eliminación y grave afectación de un grupo político o social determinado" (Uprimny, R. y Saffón, M. P. 2006, p. 23) ${ }^{11}$.

En esta edición también se indaga por los aspectos deshumanizantes de esta práctica. De acuerdo con Arias (2006, pp. 2-7), la desaparición forzada no es solo una pretensión del ente criminal para borrar toda huella que pueda inculparle. Además de ello es un dispositivo de terror que opera sobre la base de impedir el duelo, de prolongar el dolor, de evitar el ritual de despedida, de posponer para siempre aquel acto simbólico que permite a los familiares de la víctima tramitar la pérdida y despedirse del ser amado. Los efectos emocionales, tanto individuales como colectivos, están garantizados:

La desaparición forzada en esencia impide el conocimiento del paradero y la suerte de las víctimas, con lo cual, además de dificultar el trámite de los duelos, crea una zona de ambigüedad que altera los procesos individuales y familiares relacionados con el ciclo vital: no

\footnotetext{
11 Ello explicaría el lazo que une las víctimas principales de este delito: los sectores minoritarios pertenecientes a grupos políticos o las personas más vulnerables y marginales de la sociedad. De esta manera se constituye en un accionar de los grupos armados, de todos 'los ejércitos', pero principalmente de los ejércitos paramilitares como lo demuestran las cifras atribuibles a tales grupos y los diferentes estudios sobre el fenómeno.
} 
se avanza pero no se retrocede, no se crece, se está allí, atrapado en medio de la incertidumbre. Al no conocer el estado y el destino del ser querido, surgen sentimientos de perplejidad, angustia y culpa, en la permanente compañía de la ausencia. Y también porque después de la desaparición, en muchos casos los familiares de las víctimas siguen siendo hostigados y perseguidos para que no interpongan denuncia o cesen en sus esfuerzos por encontrar a sus allegados y señalar a los responsables (2006, p. 4).

Otras preguntas sobre este fenómeno, vinculadas a las condiciones que han hecho posible que un crimen de esta magnitud suceda sin que haya una reacción de la sociedad, quedan también allí planteadas:

¿Cuál es el dispositivo de tenaza social que emplea el sistema de desaparición que limita a tal extremo la capacidad de respuesta social? [...] ¿Cómo es que logra ser tan efectivo que pese a la conciencia sobre la ocurrencia de los crímenes, resulta siendo más poderoso el terror al punto de hacer inviable la expresión de rechazo o cuando menos la posibilidad de auxilio a las víctimas? ¿Cómo entender, pues, aquello que parece obrar como una especie de mecanismo capaz de paralizar al conjunto social, mudo cuando no renuente a escuchar lo que ocurre alrededor? (Arias, 2006, p. 3).

La primera intención que se avizora es la de de borrar los rostros y los rastros de las víctimas y perpetuar la impunidad. De igual manera, podría pensarse que la aparente indiferencia de la sociedad en su conjunto es también un efecto de este crimen, pues logra el cometido de instalar el terror y resquebrajar los vínculos personales, familiares y sociales. Su objetivo es también romper el tejido social. Finalmente, y es necesario insistir en ello, este tipo de estudios o informes ${ }^{12}$ que dan cuenta de este fenómeno son leídos por un número de personas muy reducido, y las cifras, las noticias sobre el tema, llegan a través de los medios masivos de información con un enfoque reduccionista y secundario, de tal manera que no logran conmover a la ciudadanía en general.

A pesar de que este drama lo sufren silenciosamente muchos de nuestros vecinos o que solo nos baste con salir del muro de 
concreto -aquel que encierra las ciudades y las separa aparentemente de los coletazos del conflicto social y armado, salir a las carreteras, a las regiones, a los pequeños pueblos blancos extraviados en las montañas azules que vemos a lo lejos, para darnos cuenta que la tragedia nos toca a todos y que sus efectos se viven ahora y seguirán a futuro incrustados en el seno de esta sociedad, pese a ello esto no nos afecta. No significa lo mismo la lectura de estos informes y estas fuentes documentales para un periodista, un investigador o un defensor de derechos humanos que para el ciudadano del común. En síntesis, para la ciudadanía en general "esto no nos pasa" o por lo menos no pasa por nuestra experiencia.

Muchos de los jóvenes que se educan en nuestras universidades y que leen día a día textos de su disciplina, no saben, no han leído, no comprenden que los cuerpos de cientos de personas han sido arrojados a los ríos más caudalosos y extensos que hacen parte de nuestra hidrografía y que hoy se cuentan como un número más en las cifras sobre desaparecidos. En su geografía colombiana y en su historia reciente no aparece el mapa del horror que la guerra ha dejado a su paso.

Los textos narrativos, quizá, puedan llegar aquí a llenar el vacío de memoria que transita en esta 'sociedad de la información'. La narrativa, nos recuerda Mendoza (2006), se ubica siempre en este ámbito de la memoria, y solo hay memoria cuando hay experiencia vivida. La experiencia de la lectura, de testimonios y relatos que mediante la escritura literaria resguardan en lo impreso el dolor de esta tragedia, permite entonces su comprensión esencial. Y allí también hay saber: "Saber de un modo", saber sobre nosotros mismos. Es otro modo de conocer y otro modo de conocimiento (Cfr. pp. 6-13).

En cuanto a la posibilidad de que la lectura de ciertos textos narrativos permita gestar una memoria colectiva, es importante "resaltar que cuando se narra no solo se pronuncia una vivencia, pues también se ponen de manifiesto las formas que caracterizan al propio grupo" (Mendoza, 2006, p.12). Para Mendoza, en tanto la narrativa lleva al terreno de lo conocido la experiencia, y también dota de sentido lo ocurrido en una colectividad, esta deviene en marco social, en punto de apoyo en el que se sostienen y contienen los recuerdos (Cfr. p. 13).

¿Cómo contar entonces la historia de la desaparición forzada en Colombia a nuestros jóvenes de tal manera que vuelvan la mirada hacia sí mismos y se digan: "esto no puede ser, no puede seguir siendo"? O mejor: “¿cómo contar una historia poco creíble, cómo suscitar la imaginación de lo inimaginable si no es elaborando, trabajando la realidad, poniéndola en perspectiva? ¡Pues con un poco de artificio!" (Semprún, citado por Mendoza, 2006, p. 12). 
La lectura literaria en tanto experiencia del sentir, pensar y vivir el dolor de los otros, nos ofrece aquí, sin duda, una condición de posibilidad.

\section{Literatura y desaparición forzada: "Vivir sin los otros"}

“...Me preguntaba si la desaparición no era acaso una ruta invisible, un estado del alma desalojado intempestivamente del mundo de las cosas concretas, como un insomnio sin imágenes, un velorio sin muerto o una inmortal agonía."

Fragmento. Vivir sin los otros

En "El delirio de las palabras" (2004) Bárcena se pregunta por la educación que está basada aún en la presencia, en el encuentro entre rostros y cuerpos, en la carne de las palabras: "¿qué puede decirnos acerca de estos silencios-otros, de estos gritos-otros, de estos dolores que nos enmudecen?". También se pregunta: "Y si la dicha, o lo que vagamente llamamos felicidad, es el horizonte que pretendemos dibujar como tensión de la experiencia educativa ipor qué hablar del dolor y de las posibilidades de un aprendizaje a partir de su íntima y silenciosa experiencia? ¿Qué forma el dolor? ¿Cuál es su figura?" (2004, p. 276).

Pero sabemos bien que en la educación no basta con ofrecer nuestra palabra o nuestro testimonio y abrirse al diálogo con el otro. Es necesario, pero no suficiente. Menos aún lo es para el tema que nos ocupa. Para comprender el dolor de una familia que guarda en su seno la ausencia de un desaparecido, para reconstruir la figura del dolor, es necesario que nuestro propio cuerpo, nuestra palabra atraviese el umbral de la experiencia. Y si "el único sustituto de la experiencia que nos ha sido dado vivir es el arte y al literatura" (Bárcena y Mélich, 2010, p. 58), es entonces posible que en la experiencia estética y poética de la lectura de los libros que nos narran este drama humano y silenciado de la desaparición forzada, hallemos un resquicio para ese saber-otro de nuestra historia. Para narrar un pasado que no pasa, para comprender este presente continuo del conflicto armado y social del país que deja permanentemente dibujada una estela de padecimiento en muchos de los rastros que no vemos y 
de los rostros que no reconocemos $^{13}$. Escuchemos, por ejemplo, esta historia:

Imaginemos el rostro de Ramiro Díaz. Un mesero locuaz, festivo, tan entrañable como despreocupado. Padre de cuatro hijas y enamorado de Betty, su esposa. Ramiro está el 6 de noviembre de 1985 en la cafetería del Palacio de Justicia y atiende a una periodista que toma un café mientras cubre las últimas noticias de un tratado de extradición. Imaginemos ahora a este padre contándole a sus hijas la épica que vivió en los dos días de retoma del Palacio. Ramiro hace de este trágico evento un jocoso recuerdo, pues el autor de esta novela nos ha construido un personaje para quien la alegría no admite cuestionamientos. Este mesero, según el relato, solía recomponer la angustia de un momento y volverla un estribillo, una fábula sobre la propia existencia en la que siempre hay que reírse del infortunio, como solo lo saben hacer las mentes más excelsas y brillantes.

Volviendo a la escena, el hombre les cuenta a sus hijas cómo su cuerpo esquivó unas balas al tiempo

13 Quizá es por eso que en ciertos muros de la ciudad de Bogotá e incluso en algunas paredes de nuestros claustros universitarios, de manera reciente hemos podido observar unos murales que narran la tragedia de las desapariciones de otro modo: Rostros a veces visibles y otros apenas delineados por sombras nos miran y al acercarnos un rompecabezas de espejos rotos nos permite ver nuestro propio rostro reflejado en la pared. Es toda una apuesta estética, ética y política. Es la obra de arte en la ciudad contándonos algo e interpelando al ciudadano al mismo tiempo. que protegía la vida de un rehén. Correr allí, ayudar acá, unirse a la labor militar cuyo oficio le era conocido, pues en otro tiempo había pertenecido a esta institución. Para él, todo habría valido la pena con el fin de ayudar a las fuerzas armadas de Colombia a recuperar 'el orden y la libertad'.

Este diálogo que sostiene con sus hijas es una invención que solo el personaje pudo contemplar en su mente. Fernando González, el autor de "Vivir sin los otros", una novela en la cual se narra esta historia de amor con el trasfondo de los sucesos históricos de la toma y retoma del Palacio, quizás también hubiese querido registrarlo al final de sus páginas, como una suerte de justicia literaria ante tanta ignominia y crueldad juntas ejercidas sobre este personaje. En efecto, Ramiro es sacado con vida del Palacio hacia la Casa del Florero, de ahí será llevado finalmente hacia un no-lugar, hacia la nada.

La invención de esta escena le pertenece también al lector. Es parte de su experiencia de lectura: singular en su propia subjetividad y a la vez plural en las posibilidades interpretativas, estéticas y sociales que trae consigo. Pero ahora que un escritor ha reconstruido con un lenguaje literario la undívaga presencia y ausencia de este personaje a través de una novela, su recuerdo permanece indeleble en el lector. La obra puede ser un pre-texto para repasar el tejido desconocido de esta 
memoria de nación a través de otros registros estéticos y de otras fuentes documentales.

Si bien la literatura no tiene como objeto promover o desarroIlar ciertas actitudes éticas, ser un documento de carácter histórico o suplir los vacíos de la formación o de la enseñanza, pues ella es ante todo y en sí misma una forma de arte, ineludiblemente su lectura se inscribe en un marco social que nos remite a la relación de los seres humanos con el mundo en que viven y que han construido, de los seres humanos entre sí y del ser humano consigo mismo. ¿Acaso la sustancia de la literatura no es todo lo que los seres humanos han pensado, sentido, creado o vivido?, se pregunta Louise Rosenblatt en una de sus obras.

En el péndulo descrito por la autora (2002), que va del énfasis social de la lectura de una obra literaria ${ }^{14}$ hasta la defensa per se de su valor estético, su tesis viene a bien frente a la idea que se ha tratado de delinear en esta reflexión: "No debería existir contradicción entre estas dos fases del arte que, de hecho, están inextricablemente relacionadas entre sí... El incremento de la sensibilidad literaria, no menos que el fomento de la conciencia social" (p. 49). Para Rosenblatt, también la lectura literaria antes que información adicional es experiencia: "proporciona un vivir a través, no simplemente un conocer sobre" (p. 65).

Y si deviene en conocimiento, nos enseña tanto lo magnánimo de la condición humana, como su barbarie. En ese viaje que se emprende en la lectura de las vicisitudes humanas, los lectores, junto con los personajes, vuelven al pasado como si fuese un tiempo presente, un tiempo vívido, un tiempo conocido. Es el acontecimiento lo que tiene lugar en esta experiencia de lectura: "Una irrupción imprevista en un estado de cosas que mantenía un decurso continuo y un transcurrir habitual...una fractura, una quiebra, una herida en el tiempo" (Bárcena, 2004, p. 80). Y si acontece, recordemos también con Larrosa, "eso me pasa", eso nos pasa.

En esta lectura no importa entonces qué tan competente es el estudiante para recuperar 'el significado' de lo leído o qué tan hábil sea para responder a un cuestionario de preguntas para verificar la comprensión, pues leer en tanto experiencia del acontecimiento no precisa de esa relación entre causas y efectos

14 Énfasis que muchas veces adquiere en la enseñanza fines meramente moralizantes o aleccionadores, de lo cual nos alerta la autora en su libro. La perspectiva ética o axiológica que aquí se defiende no intenta situarse en este carácter instrumental descrito ampliamente por Rosenblatt en su libro "La literatura como exploración" (2002). 
esperados. Y como la experiencia de lectura es siempre para cada cual la suya, no se trata aquí de ofrecer una nueva fórmula didáctica para enseñar o 'dar de leer', o una más de las prescripciones sobre lo que debería versar la educación.

Se trata de proponer una experiencia de lectura que les permita a nuestros estudiantes hacer al tiempo otra comprensión de país, a través de la cual sus palabras, sus ideas, sus saberes y sentimientos queden surcados por una pregunta, una inquietud, una sorpresa, un acontecimiento que supone estar presente antes en quien enseña ${ }^{15}$. Es una apuesta educativa menos previsible pero igualmente fecunda donde el "dar de leer" supone al mismo tiempo la discontinuidad y el porvenir: "El espacio vacío en el que quizá puede venir el porvenir de la palabra o la palabra del porvenir, el porvenir del pensamiento o el pensamiento del porvenir (Larrosa, 2000, p. 109).

15 En mis clases de Lengua durante los primeros semestres, además de enseñar a diferenciar macroestructuras, hacer ejercicios de producción escrita con mis estudiantes o proveer efectivamente estrategias lectoras para enfrentar la novedad que supone los textos académicos y científicos para aquellos iniciados en una disciplina, procuro además que haya lugar para una experiencia de lectura de este tipo con mis estudiantes. Recientemente leímos la novela "Los Ejércitos", del autor Evelio José Rosero, quien ganó con ella el premio Foreign Fiction Prize del diario The Independent y el II Premio Tusquest de Novela. La obra narra la historia de Ismael, un profesor jubilado que vive con su esposa en un pequeño pueblo. Otilia, así se llama la mujer, desaparece un día cualquiera... Narrar lo acontecido en el aula con esta experiencia pedagógica será posiblemente objeto de otro momento escritural.
En este marco de reflexión, enseñar a leer en la Universidad no es solo enseñar a comprender de manera 'correcta' o acceder a una infinitud de textos de la cultura, privilegiando en ellos lo que sea más útil para la formación disciplinar y profesional. Es también una suerte de búsqueda, de literatura y de autores, que permitan "formar lectores abiertos a la experiencia, a que algo les pase al leer, abiertos hacia su transformación, abiertos, por consiguiente, a no reconocerse en el espejo" (Larrosa, 2008, p. 93).

\section{A manera de epílogo}

Para la palabra imprescindible, que busca cauterizar la herida y consolarnos con su música soterrada. Juan Gustavo Cobo Borda, 2009

En Colombia hemos tenido nuestro propio holocausto, como nos lo retrata el libro que referimos en el acápite anterior y como nos lo narra a su modo la historia oficial. Y hemos vivido más que eso. ¿Cuánto tiempo seguiremos apostándole a la guerra como única salida al conflicto social y armado que vive el país hace décadas? ¿Cuántos muertos y cuántos desaparecidos más se requieren para que nuestra sociedad diga "basta"? ¿Qué tipo de educación es posible para un país en conflicto? No hay suficientes y definitivas respuestas. Pero a través de la lectura literaria siempre cabe la posibilidad de que "el recuerdo de lo que no hemos 
experimentado directamente, pero que podemos reconstruir a través de las crónicas que nos han llegado, [se] pueda romper la historia y mostrar que los derechos de los vencidos siguen vigentes" (Bárcena y Mélich, 2000, pp. 18-19).

Hoy más que nunca, nuestros jóvenes y la sociedad colombiana en su conjunto necesitan contar a sus desaparecidos y a la vez contar con ellos. Necesitamos contar sus historias, transmitirlas a las nuevas generaciones, hacerlas propias, impedir el olvido. Educar en una pedagogía de la memoria porque no olvidar es un imperativo ético: "De ahí que educar implique recordar [pues] no puede haber futuro sin memoria del pasado. Un futuro sin memoria es un futuro injusto, inmoral" (2000, p. 30). Así que esto es parte también de todo proyecto educativo de nación.

Y para no olvidar están esas fuentes documentales que nos permiten cierta comprensión del fenómeno de la desaparición forzada. Están las crónicas, los testimonios, las noticias en los medios de comunicación y las cifras que allí se registran. Pero por sí solos, como se ha venido señalando, estos datos parecen reducir el drama de las desapariciones al mero contar numérico y los lectores aparecen siempre impasibles ante esta realidad. Por ello, la literatura se erige en los vacíos de la memoria personal en su lectura y de la memoria colectiva en su registro impreso . La experiencia estética que proveen las obras literarias que recuperan la condición humana en la historia de los sobrevivientes, que nos reviven sus experiencias de dolor, que nos relatan los acontecimientos que no están en los textos de la historia oficial, fundan una posibilidad pedagógica de lo inenarrable: "Por la memoria, el poeta puede relatar los acontecimientos del pasado porque tiene el poder de estar en el pasado o, dicho de otro modo, de hacer presente lo pasado, de hacer presente lo ausente" (2000, p. 22).

La lectura de libros como el de Fernando González y otros tantos que hacen parte de la literatura nacional se constituye en una provocación al conocimiento de nuestra propia historia ${ }^{16}$.

16 "Vivir sin los otros" es una novela más entre muchas obras literarias que tratan este tema en Colombia; como bien lo anota Gaitán Bayona, en "un país irónico donde los horrores sonrojan a los números, [y] está siempre a la moda con la muerte". En su artículo "El arte de la desaparición forzada en dos novelas colombianas", este autor da cuenta de Fragmentos de una sola pieza (1995) de Alexandra Cardona y Las horas secretas (1990) de Ana María Jaramillo, "que abordan la tragedia de los desaparecidos, junto con otras novelas de escritoras colombianas que también exploran el fenómeno, como son Noches de humo (1988) de Olga Behar, Los muertos no se cuentan así (1991) de Mary Daza Orozco, y La multitud errante (2001) de Laura Restrepo. En estas obras las historias de amor y de cuerpos femeninos afectados en sus posibilidades afectivas y eróticas se convierten en poderosos lentes para explorar traumas profundos de la nación" (Cfr. Revista Espéculo, 2010). 
Estas lecturas recuperan, además, el insoslayable papel de la experiencia estética para acercarnos al dolor de los otros y sentirlo como propio. Si ello no es suficiente o son demasiadas páginas y el tiempo apremia, basta también con la experiencia singular y plural de una lectura poética. Tal vez baste un poema:

\section{Desaparecidos}

Por Mario Bendetti Están en algún sitio / concertados desconcertados / sordos buscándose / buscándonos bloqueados por los signos y las dudas contemplando las verjas de las plazas

los timbres de las puertas / las viejas azoteas ordenando sus sueños sus quizá convalecientes de su olvidos
privada muerte privada

nadie les ha explicado con

certeza

si ya se fueron o si no si son pancartas o temblores sobrevivientes o responsos ven pasar árboles y pájaros e ignoran a qué sombra

pertenecen cuando empezaron a desaparecer hace tres cinco siete ceremonias a desaparecer como sin sangre como sin rostro y sin motivo

vieron por la ventana de su ausencia lo que quedaba atrás / ese andamiaje de abrazos cielo y humo cuando empezaron a desaparecer como el oasis en los espejismos a desaparecer sin últimas palabras tenían en sus manos los trocitos de cosas que querían están en algún sitio / nube o tumba están en algún sitio / estoy seguro allá en el sur del alma es posible que hayan extraviado la brújula y hoy vaguen preguntando dónde carajo queda el buen amor porque vienen del odio. 


\section{Referencias}

Arias Morales, F. J. (2006). Desaparición forzada. Una mirada psicosocial a la danza entre la noche y la niebla. En: Razones y Emociones No. 18 pp. 2-7 [en línea] Disponible en: http://www.dos-mundos.org/pdf/revista/sinras_018.pdf, recuperado 7 de junio de 2010

Bárcena, F. y Mélich, J-C. (2000). La educación como acontecimiento ético. Natalidad, narración y hospitalidad. España: Paidós.

Bárcena, F. (2004). El delirio de las palabras. Ensayo para una poética del comienzo. España: Herder.

Cobo Borda, J. G. (2009). Antígona y Orfeo conjuran el horror. En: Cuentos para no olvidar el rastro. Bogotá: Fundación Dos mundos.

Freire, P. (1997). La educación como práctica de libertad. México: Siglo XXI editores.

Freire, P. (1989). Pedagogía del oprimido. México: Siglo XXI editores.

Gaitán Bayona, J. L. (2010). El arte de la desaparición forzada en dos novelas colombianas. En: Espéculo. Revista de estudios literarios. Universidad Complutense de Madrid. [en línea] Disponible en: http://www.ucm.es/info/especulo/numero46/ desaparici.html

González, S. F. (2010). Vivir sin los otros. Los desaparecidos del Palacio de Justicia. Bogotá: Ediciones B.

Jurado, V. (2001). La literatura como provocación hacia el conocimiento en la educación. En: Escritores, profesores y literatura. Colombia: Plaza \& Janes, pp. 91-98.

Larrosa, J. (2000). Dar a leer, dar a pensar...quizá entre literatura y filosofía. En: Filosofía y literatura en la educación de los jóvenes y los niños. Kohan, W. \& Waskman V. (comps) Brasil: novedades educativas. pp. 101-110 [en línea] disponible en: http://teorialiteraria2009.files.wordpress.com/2009/04/ larrosa-jorge-dar-de-pensar-dar-de-leer-quiza.pdf

Larrosa, J. (2008). Sobre la experiencia. En: Aloma. Disponible en: http://www.raco.cat/index.php/Aloma/article/viewFile/103367/154553

Mendoza, G. (2004). Las formas del recuerdo. La memoria narrativa. En: Athenea digital, No. 6.

Rosenblatt, L. M. (2002). La literatura como exploración. México: 
Fondo de Cultura Económica. Steiner, G. (2003). Lenguaje y silencio. Barcelona: Gedisa.

Uprimny, R. y Saffón M. P. (2006). Los retos jurídicos de la desaparición forzada: de la lucha por el reconocimiento a la lucha por la eficacia de un crimen atroz. En: Razones y Emociones No. 18 pp. 21-26 [en línea] disponible en: http://www. dos-mundos.org/pdf/revista/sinras_018.pdf, recuperado 7 de junio de 2010

\section{Notas periodísticas en páginas web}

www.semana.com [en línea], (Informe especial miércoles 15 de noviembre de 2006) "Los desaparecidos forzados en Colombia ¿cuántos se buscan?» disponible en: http://www.semana. com/on-line/desaparecidos-forzados-colombia-cuantos-buscan/98213-3.aspx, recuperado enero de 2010.

www.semana.com [en línea], (sábado 17 de octubre de 2009) «El crimen invisible» disponible en: http://www.semana. com/nacion/crimen-invisible/130145-3.aspx, recuperado enero de 2010.

www.wradio.com.co, Agencia EFE [en línea], (Mayo 24 de 2011), «ONU Desaparición forzada en Colombia es de 'dimensiones escalofriantes'» disponible en: http://www.wradio.com.co/ nota.aspx?id=1477490, recuperado mayo de 2011.

www.eliempo.com [en línea] (13 de diciembre de 2010) "Son 51 mil los desaparecidos en Colombia en las últimas décadas» disponible en: http://www. eltiempo.com/justicia/ARTICULO-WEB-NEW_NOTA_INTERIOR-8584522.html, recuperado enero de 2011.

\section{Informes especiales}

Fundación Dos mundos (2006). Desaparición forzada. Una mirada psicosocial a la danza entre la noche y la niebla. En: Edición especial Razones y Emociones No. 18 [en línea] disponible en: http://www.dos-mundos. org/pdf/revista/sinras_018.pdf, recuperado 7 de junio de 2010

Haugaard, L. \& Nicholls K. (2010). Rompiendo el silencio. En la búsqueda de los desparecidos en Colombia. Grupo de trabajo sobre asuntos latinoamericanos y la Oficina en los Estados Unidos sobre Colombia. [en línea] disponible en: http://www.lawg. org/storage/documents/Colombia/RompiendoElSilencio.pdf

CNRR, Grupo de Memoria Histórica (2009). Memorias en Tiempo de Guerra Repertorio de iniciativas. Colombia, octubre de 2009. Disponible en: http://www. memoriahistorica-cnrr.org.co/ archivos/arc_docum/memoria_ tiempos_guerra_baja.pdf 